\title{
Place learning in virtual space III: Investigation of spatial navigation training procedures and their application to fMRI and clinical neuropsychology
}

\author{
KEVIN G. F. THOMAS \\ University of Arizona, Tucson, Arizona \\ and University of Arizona South, Sierra Vista, Arizona \\ MING HSU, HOLLY E. LAURANCE, and LYNN NADEL \\ University of Arizona, Tucson, Arizona \\ and \\ W. JAKE JACOBS \\ University of Arizona, Tucson, Arizona \\ and University of Arizona South, Sierra Vista, Arizona
}

\begin{abstract}
This paper describes the utilization of a desktop virtual environment task, the Computer-Generated (C-G) Arena, in the study of human spatial navigation. First, four experiments examined the efficacy of various training procedures in the C-G Arena. In Experiment 1, participants efficiently located a hidden target after only observing the virtual environment from a fixed position (placement learning). In Experiment 2, participants efficiently located a hidden target after only observing an experimenter search the virtual environment (observationallearning). In Experiment 3, participants failed to display a latent learning effect in the virtual environment. In Experiment 4, all training procedures effectively taught participants the layout of the virtual environment, but the observational learning procedure most effectively taught participants the location of a hidden target within the environment. Finally, two experiments demonstrated the application of C-G Arena procedures to neuroimaging (Experiment 5) and neuropsychological (Experiment 6) investigations of human spatial navigation.
\end{abstract}

In this paper, we describe the development and application of a computer-generated nonimmersive virtual environment (VE) task ${ }^{1}$ designed to study place learning and memory in humans. This task, which we have named the Computer-Generated (C-G) Arena, was devised in response to the need for a procedure to (1) accurately and efficiently assess human spatial navigation and (2) collect

This work was supported by a grant from the McDonnell-Pew Program in Cognitive Neuroscience awarded to the last author. We gratefully acknowledge earlier support from the University of Southern California's James H. Zumberge Faculty Research and Innovation Fund. Joe Demers wrote the original program, William-James (William Cook and James Comstock) wrote the current version, and Ron Skelton and Cindy Bukach devised the first version of the ART; we thank them all. We also thank Thomas Brunner and Courtney Baker for their careful thought and valuable input. The comments of two reviewers, Richard Carlson and Daniel Weeks, were helpful in shaping the final version of the manuscript, and we thank them for their efforts. Finally, we acknowledge Nancy Barron, Murat Dag, Alma Durazo, Tonya Hancock, Maile Hatch, Mathew Horodner, Holly Jindrick, Trina Keil, Laura Moore, Sheryl Reminger, Mark Stein, Janet Stewart, Amy Stiles, Tamar Tal, and Jessica Zimmerman for their contributions in helping us obtain the data reported in this paper. Correspondence should be addressed to K. G. F. Thomas, Psychology Department, University of Arizona, P. O. Box 210068, Tucson, AZ 85721-0068(e-mail: thomaske@u.arizona.edu). human data comparable to the animal data gathered using the Morris water maze (see Morris, 1981, 1984).

The development and the availability of VE tasks such as the C-G Arena provide a convenient means of investigating human spatial navigation. Using such tasks, one can conduct empirical tests of spatial cognition theory without incurring the methodological costs of uncontrolled naturalistic navigation and the financial costs of constructing real-world analogs of tasks such as the Morris water maze (Wilson, 1997). Several studies using such technology have been reported (for a recent review, see Maguire, Burgess, \& O'Keefe, 1999; see also, e.g., Arthur, Hancock, \& Chrysler, 1997; Gillner \& Mallot, 1998; Jacobs, Laurance, \& Thomas, 1997; Jacobs, Thomas, Laurance, \& Nadel, 1998; May, Péruch, \& Savoyant, 1995; Ruddle, Payne, \& Jones, 1997; Tlauka \& Wilson, 1996). Some of those studies have found that (1) humans can make accurate judgments about metrics in real space after learning in a virtual environment (Péruch, Vercher, \& Gauthier, 1995), (2) there is good transfer of spatial information from virtual to real environments (Bliss, Tidwell, \& Guest, 1997; McComas, Pivik, \& Laflamme, 1998; Wilson, Foreman, \& Tlauka, 1997), (3) VE technology and virtual reality (VR) technology show promise in aid- 
ing neurological and neuropsychological rehabilitation (Brooks et al., 1999; Rizzo, Buckwalter, Neumann, Kesselman, \& Thiebaux, 1998; Rose, Attree, \& Johnson, 1996), and (4) such technology can help answer questions about sex- and age-related differences in spatial abilities (Astur, Ortiz, \& Sutherland, 1998; Sandstrom, Kaufman, \& Huettel, 1998; Thomas, Laurance, Luczak, \& Jacobs, 1999). In sum, the advent of VE spatial navigation tasks such as the C-G Arena might provide the same impetus for studies of spatial learning and memory in humans as the Morris water maze did for studies of spatial learning and memory in rodents (Brandeis, Brandys, \& Yehuda, 1989).

The fundamental features of the C-G Arena are these: A conventional computer monitor displays a circular arena within a large square room. Each wall of the room displays a unique set of distal cues. Humans view this arena from a first-person perspective and are instructed to manipulate the display so as to search for a square target located on the arena floor. In some conditions, the target is invisible and so offers no local cues to guide this search; in others, the target is visible. After several acquisition trials, humans typically move directly to an invisible target from any starting position.

When humans display efficient navigation (viz., by taking an accurate and direct path to an invisible target), this is evidence they have learned the spatial location of the target relative to the computer-generated distal cues. Several measures are used to estimate the efficiency of this place learning, including (1) latency to find the target on each trial, (2) length of the search path, and (3) distribution of search time in each of the four quadrants of the arena on a "probe trial," during which the target is absent from the arena.

Using the C-G Arena, Jacobs et al. (1997) showed that, in humans, place learning can occur on the basis of computer-generated distal cues alone, place learning based on such distal cues does not disengage when computer-generated proximal cues are present, and place learning generalizes from familiar to novel start locations. Furthermore, Jacobs et al. (1998) used the task to show that, in humans, place learning does not rely on any single set of distal cues, and place learning is disrupted by changes in topographical relations among distal cues. These results closely resemble those found when rats are tested in the Morris water maze (see, e.g., Fenton, Arolfo, Nerad, \& Bureš, 1994; Morris, 1981) and in dryland mazes (see, e.g., Suzuki, Augerinos, \& Black, 1980). These results also confirm predictions made by the cognitive mapping theory of O'Keefe and Nadel (1978; see also Nadel, 1991), thus demonstrating the construct validity of the C-G Arena task. ${ }^{2}$

This paper describes three variations on training procedures in the C-G Arena. Implementation of these procedures may allow researchers to study the effects of different forms of training on human spatial navigation. Furthermore, the paper describes two applications of C-G
Arena procedures, illustrating ways in which the task might be used in neuroimaging, clinical, and neuropsychological research. The paper also describes the arena reconstitution task (ART), a companion task to the $\mathrm{C}-\mathrm{G}$ Arena. The ART is a nonverbal paper-and-pencil measure of place learning that is independent of the C-G Arena task and the data collected from it. The ART may provide data congruent with those gathered from the computer task, thus establishing convergent validity in the assessment of spatial learning and memory in humans.

\section{GENERAL METHOD}

\section{Participants}

Six independent sets of data (from six separate experiments) are described here. The 166 participants in Experiments 1-4 were University of Arizona students. They were recruited from undergraduate psychology courses, and they received extra credit in exchange for their participation. The 4 participants in Experiments 5 and 6 were recruited from the University of Arizona community, and they received no compensation for their participation.

In Experiments 1-4, the data from 34 individuals were lost or discarded due to (1) a failure of the software to record data, (2) a failure of the hardware, or (3) a failure of the experimenter to properly administer the procedure. We have no reason to believe this loss biased the final analysis.

\section{Apparatus}

A personal computer (PC) and custom-designed software generated a display on a PC monitor. The monitor displayed a multicolored view of a circular arena contained within one of two square rooms, a waiting room and an experimental room, from a first-person perspective. The monitor did not display a representation of the participant.

Two pieces of software have been designed. The first was used in Experiments 1-3, in Experiments 5 and 6, and in the experiments described by Jacobs et al. (1997), Jacobs et al. (1998), Nadel et al. (1998), and Thomas et al. (1999). The second, which provides more display flexibility and better data-handling capabilities, was used in Experiment 4 . The displays generated by the programs (and thus the core tasks assigned to the participants) were, however, identical. ${ }^{3}$

Several characteristics within each of the C-G Arena rooms were set by user-def ined variables. Those variables, and examples of their settings, are outlined in Table $1 .^{4}$

The C-G waiting room. The waiting room consisted of a computer-generate d display of a large square room housing an arena. The four walls of the room were colored blue, green, red, and yellow, respectively. The ceiling of the room was colored light gray, and the floor was colored dark gray. A circular purple wall (the "arena wall") enclosed the central portion of the waiting room, thus defining the waiting room arena. All the aforementioned surfaces lacked texture.

When the PC monitor displayed a view as if the participant was standing against and facing the arena wall, that wall filled the screen. When the monitor displayed a view as if the participant was against the arena wall but turned away from it, a large portion of the arena, the surrounding room, and part of the ceiling were displayed.

Exposure to the waiting room distinguished the experimental trials from each other and, if needed, permitted the participant to practice moving in the virtual environment.

The C-G experimental room. The experimental room consisted of a computer-generated display of a large square room housing an arena. The walls of the room were arbitrarily designated North, East, South, and West. The North wall was colored light gray 
Table 1

C-G Arena Room, Target, and Motion Parameters

During Acquisition Trials of the Present Procedures

\begin{tabular}{|c|c|c|c|c|}
\hline & Experiments 1 and 2 & Experiment 3 & Experiment 4 & Experiments 5 and 6 \\
\hline \multicolumn{5}{|c|}{ Room Parameters } \\
\hline Dimensions & $3,000 \times 3,000 \times 475$ & $3,000 \times 3,000 \times 475$ & $512 \times 512 \times 128$ & $3,000 \times 3,000 \times 475$ \\
\hline Arena wall radius & 460 & 460 & 50 & 460 \\
\hline Arena wall height & 30 & 30 & 3.5 & 30 \\
\hline Participant eye height* & 15 & 15 & 2.0 & 15 \\
\hline \multicolumn{5}{|c|}{ Target Parameters $\dagger$} \\
\hline Size & $142 \times 142$ & $142 \times 142$ & $10 \times 10$ & $142 \times 142$ \\
\hline \multicolumn{5}{|c|}{ Motion Parameters $\ddagger$} \\
\hline Move quantum & 10.0 units & 4.0 units & 0.8 units & 4.0 units \\
\hline Movement rate & 20-30 units/sec & $20-30$ units/sec & 20-30 units/sec & $20-30$ units/sec \\
\hline Turn quantum & $3.0^{\circ}$ & $1.0^{\circ}$ & $1.0^{\circ}$ & $1.0^{\circ}$ \\
\hline Turn rate & $30^{\circ}-40 \% \mathrm{sec}$ & $30^{\circ}-40 \% \mathrm{sec}$ & $30^{\circ}-40 \% \mathrm{sec}$ & $30^{\circ}-40^{\circ} / \mathrm{sec}$ \\
\hline
\end{tabular}

Note-Unless otherwise indicated, all measurements are in C-G Arena units. If we, for the sake of convenience, take the length of a stride ( 10 units) to be the equivalent of $1 \mathrm{~m}$, then, in the first three experiments, the room dimensions were $300 \times 300 \times 47.5 \mathrm{~m}$, the arena wall was $3 \mathrm{~m}$ high and had a radius of $46 \mathrm{~m}$, the target measured $14.2 \times 14.2 \mathrm{~m}$, and the participants moved at $2-3 \mathrm{~m} / \mathrm{sec}$. *The PC monitor displays all views of the arena from a first-person perspective and as if the eyes of the participant are a certain user-defined distance (an "eye height") from the floor of the C-G Arena rooms. IIn all six experiments, the target was located in the center of in the Northwest quadrant of the arena. In Experiments 1-3 and Experiments 5 and 6, the center of the target was approximately 234 units from the closest part of the arena wall. In Experiment 4, the center of the target was approximately 24 units from the closest part of the arena wall. \$The move quantum approximates the shift in the participant’s view of the C-G Arena with each forward or backward movement of the joystick. The movement rate approximates the speed with which the participant's view of the C-G Arena shifted when the joystick was held in either a forward or a backward position. Similarly, the turn quantum approximates the shift in the participant's view of the C-G Arena with each right or left movement of the joystick, and the turn rate approximates the speed with which the participant's view of the C-G Arena shifted when the joystick was held in either a left or a right position.

and displayed a door flanked by two windows; the East wall displayed six-and-one-half black arches; the South wall was colored light gray and displayed three centered windows; and the West wall displayed a red brick pattern. The ceiling, floor, and arena wall of the experimental room, and the manner in which the PC monitor displayed various views within the arena, were identical to those of the waiting room. ${ }^{5}$

Quadrants. The arena in the experimental room was divided into four imaginary quadrants. Moving clockwise, the first was named Northwest (NW; because it was located in the corner formed by the junction of the North and West walls), the second Northeast (NE), the third Southeast (SE), and the fourth Southwest (SW). Lines delineating the quadrants were not a part of the computer-generated display. Figure 1 provides an illustration of each of the four quadrants.

Target. A square target was located on the floor of the C-G experimental room. Under some experimental conditions, the target was a part of the display and was colored plain blue. Under other experimental conditions, the target was initially invisible to participants (i.e., its color was initially identical to that of the surrounding arena floor). When the participant moved across the place occupied by the invisible target, that target became visible (i.e., a featureless blue square appeared on the arena floor). If the participant subsequently moved off that initially invisible target, the target again became invisible.

Under every experimental condition, a brief computer-generated tone sounded with each movement the participant made while on the target. When the participant moved off the target, the tone no longer sounded. Standing on the target did not change the eye height of the participant.

Movement. The participants used a joystick to move in the C-G Arena. Moving the joystick directly forward or backward moved the participant's view of the arena forward or backward. Holding the joystick directly forward or backward moved the participant's view forward or backward at a constant rate until a new movement was initiated or the joystick was returned to its rest position.

Moving the joystick left or right turned the participant's view of the arena to the left or the right, respectively, as the participant remained in place. Holding the joystick in either a left or a right position turned the participant in that direction at a constant rate until a new movement was initiated or the joystick was returned to its rest position.

The participant moved from the waiting room to the experimental room by striking the space bar on the PC keyboard. The participant moved from the experimental room to the waiting room by striking the space bar while standing on the target.

\section{Procedure}

Each experiment described below followed the general procedure outlined in this section. Parametric changes are detailed within the individual descriptions of each experiment.

Informed consent and instructions. Each participant entered the laboratory, read and signed a consent form, and was randomly assigned to an experimental group. Each then received standard verbal instructions about the task and about movement in the virtual environment. (Please visit http://w3.arizona.ed u/ arg/papers/ place3.html to view an example of these instructions.)

These instructions were designed to prepare the participant for the VE display they would see and, perhaps more importantly, to bring the following classes of behavior under rule governance: the directions in which the participants could move the joystick while exploring the C-G Arena (e.g., "pushing the joystick left or right will turn you in the corresponding direction, but will not move you sideways"), and how and when they could move between the C-G waiting room and the C-G experimental room (e.g., "while you are standing on the target, you can transport yourself to the practice room by pressing the space bar"). The participants in different experimental groups re- 


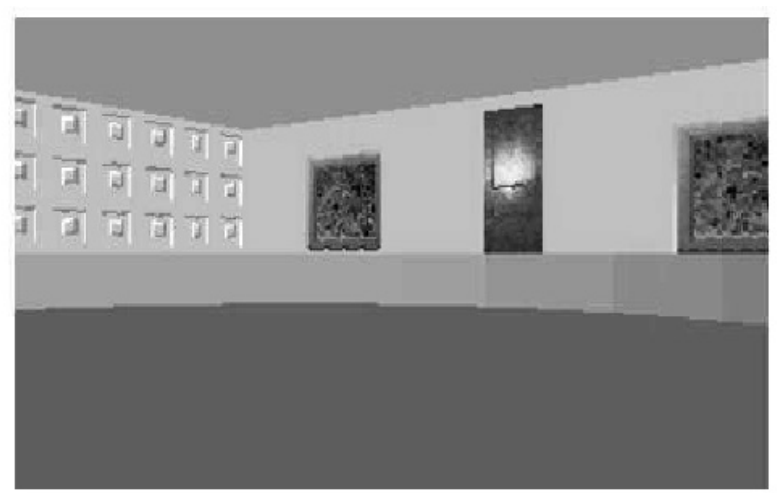

NW Quadrant

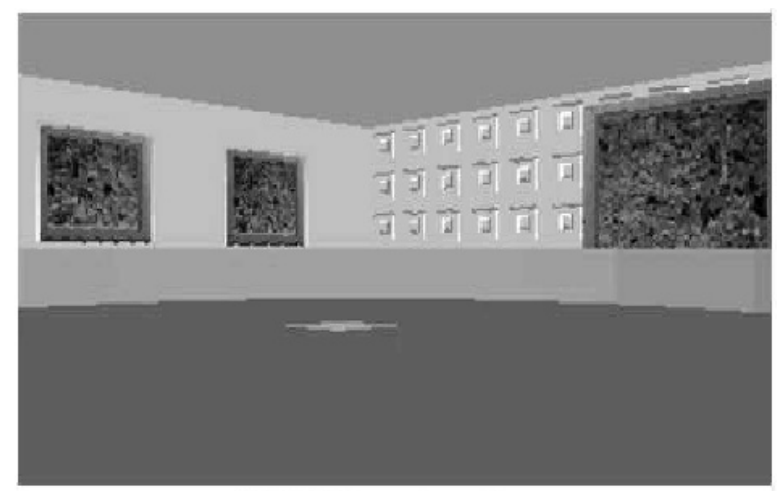

SW Quadrant

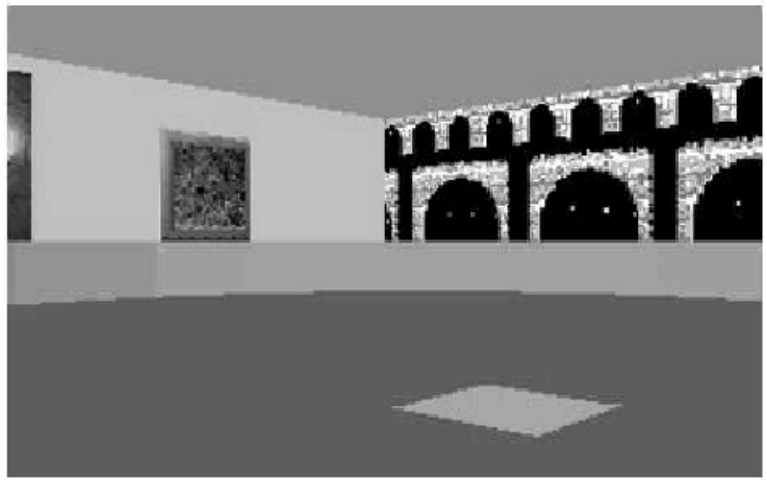

NE Quadrant

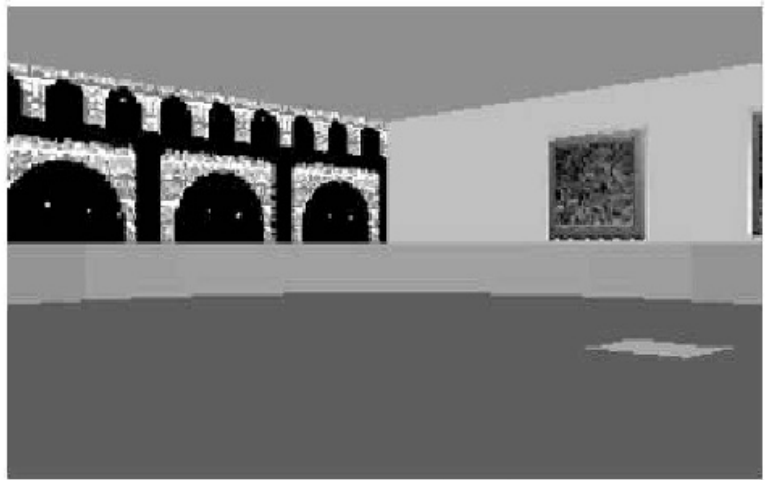

SE Quadrant

Figure 1. Four representations of the C-G experimental room as seen by the participants. The upper left panel illustrates the participants' view of the NW quadrant as seen from the opposite (SE) quadrant. Portions of the North and West walls, as well as much of the ceiling, floor, and arena wall, are visible. The upper right panel illustrates the participants' view of the NE quadrant as seen from the opposite (SW) quadrant. Portions of the North and East walls are visible. The lower right panel illustrates the participants' view of the SE quadrant as seen from the opposite (NW) quadrant. Portions of the South and East walls are visible. The lower left panel illustrates the participants' view of the SW quadrant as seen from the opposite (NE) quadrant. Portions of the South and West walls are visible.

ceived additional instructions appropriate to the training procedures with which they would be presented. An experimenter remained in the laboratory throughout the experiment to answer questions about the instructions or about the experimental procedures.

Acquisition phase. The participants received a series of acquisition trials. Each participant began the acquisition phase in the center of the C-G waiting room. After striking the space bar, the participant teleported to a pseudorandomly determined start position at the circumference of the $\mathrm{C}-\mathrm{G}$ experimental room.

The participant then searched for an invisible target on the arena floor. As described above, when the participant moved across the place occupied by the target, the target icon became visible, and a brief computer-gener ated tone sounded with each movement. While standing on the target, striking the space bar ended the trial and returned the participant to the middle of the $\mathrm{C}-\mathrm{G}$ waiting room. Striking the space bar while in the waiting room returned the participant to the experimental room and began the next acquisition trial. If the participant did not find the target, stand on it, and strike the space bar within the time limit, the trial terminated, and the participant was returned to the middle of the waiting room.

Probe trial. Immediately following the acquisition trials, each participant received a single probe trial. The probe trial was identi- cal to the acquisition trials with these exceptions: (1) The target, unbeknownst to the participant, was not in the arena, and (2) after the time limit was reached, the trial terminated, and the participant was presented with a blank screen, indicating the end of this portion of the task.

Data analyses. C-G Arena software generates two separate data files for each participant run through the user-specified series of trials. The first data file contains information about several different aspects of the participant's performance on each trial, including the following: (1) path length, the distance traveled from the start point to the target; (2) latency, the time required to find the target; (3) target crossings, the number of times the participant moved across the space occupied by the target; (4) dwell time, the time spent in each of the arena quadrants; and (5) heading direction, the direction in which the participant was headed at specific intervals during the trial. The second data file contains a pixel-by-pixel recording of the participant's experience in the C-G Arena. From this data file, one can generate a top-down image of the search path taken in the arena on each trial. ${ }^{6}$

In the experiments described here, we used path length, latency, and dwell time as our primary dependent variables. The Type I error rate $(\alpha)$ was set at .05 for all statistical decisions. 
Table 2

Path Length to Invisible Target on First Acquisition Trial of Experiments 1 and 2

\begin{tabular}{|c|c|c|c|}
\hline Group & $n$ & $M$ & SEM \\
\hline \multicolumn{4}{|c|}{ Experiment 1: Placement Learning } \\
\hline Control & 13 & $3,890.36$ & 684.30 \\
\hline PL1 & 10 & $3,068.18$ & 377.67 \\
\hline PL5 & 10 & $1,867.34$ & 444.64 \\
\hline \multicolumn{4}{|c|}{ Experiment 2: Observational Learning } \\
\hline Control & 18 & $3,981.10$ & 612.62 \\
\hline Observational learning & 18 & $1,714.57$ & 330.63 \\
\hline
\end{tabular}

Note-The measurements of path length are in C-G Arena units.

\section{EXPERIMENTS 1-3}

Each of the first three experiments described here was conducted with the aim of establishing the efficacy of a particular training procedure in the $\mathrm{C}-\mathrm{G}$ Arena. The participants in these experiments were 109 undergraduate students (57 males and 52 females), between 17 and 24 years of age ( $M=19.26$ years). Male and female participants were evenly distributed across experimental and control groups.

\section{EXPERIMENT 1 Placement Learning}

\section{Method}

Two groups of participants received a placement learning phase immediately before acquisition and probe trials. The placement learning phase began with the participant entering the C-G waiting room. When the participant pressed the space bar on the keyboard, he or she teleported to the arena in the $\mathrm{C}-\mathrm{G}$ experimental room. The participant entered facing the arena wall and in the middle of a visible plain blue target. The target was always in the same location. The participant was allowed to move forward and backward and rotate left and right on the target but was not allowed to move off the target onto the arena floor. The trial terminated after $60 \mathrm{sec}$, and the participant was automatically returned to the middle of the waiting room. One group of participants (Group PL1) received one such trial, and the other (Group PL5) received five such trials.

Immediately following this training phase, the participants in Groups PL1 and PL5 received a series of seven acquisition trials and a probe trial. During the acquisition trials, an invisible target was located in the same place the visible target had been located during the placement learning trials. The participants in a control group received an identical series of acquisition trials and an identical probe trial, without previous placement learning trials.

\section{Results}

The most critical data reflect the performance of the participants on the first acquisition trial. If the participants in Groups PL1 and PL5 acquired and remembered any spatial information from the placement learning trials, that information, and its attendant advantages, should best be detected on the first acquisition trial.

Table 2 presents the mean path length to the invisible target during the first acquisition trial for each of the three groups. A one-way between-groups analysis of variance (ANOVA) conducted on these data detected a significant main effect of group $[F(2,30)=3.79]$. A set of post hoc orthogonal contrasts conducted on these data detected a significant difference between the mean path length of the participants in the control group and that of the participants in Group PL5 $[t(30)=2.73]$ and no significant difference between the mean path length of the participants in the control group and Group PL5 taken together and that of the participants in Group PL1 $[t(30)<1]$. This set of decisions implies the following order of mean path lengths on the first acquisition trial: Group PL5 < Group PL1 < control group. This order of means suggests that the participants in both placement learning groups took a more direct path to the target on the first acquisition trial than did the participants in the control group.

\section{EXPERIMENT 2 Observational Learning}

\section{Method}

One group of participants received an observational learning phase immediately before acquisition and probe trials. Each participant in this group observed an experimenter receive a series of four acquisition trials. During those trials, the experimenter used the PC keyboard to move in the C-G Arena and to locate the invisible target. The experimenter sat directly in front of the participant so that the participant could view the display on the PC monitor but could not see the experimenter's hands on the keyboard. During each trial, the experimenter moved to the target as quickly and directly as he or she could and, after locating it, rotated once before striking the space bar to end the trial.

Immediately following this training phase, the participants in the observational learning group received a series of seven acquisition trials and a probe trial. During the acquisition trials, an invisible target was located in the same place the invisible target had been located during the observational learning trials. The participants in a control group received an identical series of acquisition trials and an identical probe trial, without previous observational learning trials.

\section{Results}

Again, the most critical data reflect the performance of the participants on the first acquisition trial. Table 2 presents the mean path length to the invisible target during that trial for the observational learning and control groups. A one-way between-groups ANOVA conducted on these data detected a significant main effect of group $[F(1,34)=10.60]$. These data thus indicate that the participants in the observational learning group took a more direct path to the target on the first acquisition trial than did the participants in the control group.

\section{EXPERIMENT 3 Latent Learning}

\section{Method}

Two groups of participants received a latent learning phase immediately before acquisition and probe trials. The latent learning phase consisted of a series of four trials in a $\mathrm{C}-\mathrm{G}$ experimental room. The participants in Group LL-A were placed into an experimental room identical to that described in the General Method section. The participants in Group LL-B were placed into an experimental room that differed only in terms of the stimuli present on the 
Table 3

Time to Invisible Target on First Acquisition Trial and Relocation Trial of Experiment 3 (Latent Learning)

\begin{tabular}{|c|c|c|c|c|c|}
\hline \multirow[b]{2}{*}{ Group } & \multirow[b]{2}{*}{$n$} & \multicolumn{2}{|c|}{ First Acquisition Trial } & \multicolumn{2}{|c|}{ Relocation Trial } \\
\hline & & $M$ & SEM & $M$ & $S E M$ \\
\hline Control & 14 & 129.00 & 16.23 & 69.93 & 15.45 \\
\hline LL-A & 14 & 64.36 & 13.76 & 57.14 & 14.62 \\
\hline LL-B & 14 & 79.43 & 14.52 & 76.29 & 17.08 \\
\hline
\end{tabular}

Note-The measurements of time to target, or latency, are in seconds.

walls of the room; in this room, the North wall was colored light gray and displayed three centered doors; the East wall was colored light gray and displayed three shields, one in each of its upper corners and one in its center; the South wall was colored black and displayed a centered picture of the earth; and the West wall was colored light gray and displayed two musical notes, one in each of its upper corners.

Training for the participants in each of the two groups began in the $\mathrm{C}-\mathrm{G}$ waiting room. After striking the space bar, the participant teleported to a start position in the $\mathrm{C}-\mathrm{G}$ experimental room. No target was present in the arena during the latent learning trials. The participants were thus simply instructed to "Take a good look around the experimental room and explore it as much as you can." The trial terminated after $60 \mathrm{sec}$, and the participant was automatically returned to the middle of the waiting room. Striking the space bar while in the waiting room returned the participant to the experimental room and began the next latent learning trial.

Immediately following this training phase, the participants in Groups LL-A and LL-B received a series of eight acquisition trials and a probe trial. The participants in a control group received an identical series of acquisition trials and an identical probe trial, without previous latent learning trials.

\section{Results}

The most critical data in this experiment reflect the performance of the participants on the first acquisition trial and on the trial immediately following the first time they located the target (for convenience, we will refer to the latter as the relocation trial). The first acquisition trial data are critical because, if the participants in both latent learning groups located the target more rapidly and directly than the participants in the control group, then the argument can be made that their previous experience in the virtual environment, and with joystick movement in the C-G Arena, produced an advantage. On the other hand, if, on the first acquisition trial, the participants in Group LL-A located the target more rapidly and directly than the participants in the other groups, then the argument can be made that their knowledge of the distal cues in the C-G experimental room, and the relations between those cues (i.e., the layout of the room), produced an advantage.

The relocation trial data are critical because, if the participants in Group LL-A relocated the target more rapidly and directly than the participants in the other two groups, then the argument can be made that their knowledge of the layout of the C-G experimental room, now added to their knowledge of the target location, produced an advantage.

Table 3 presents the mean latency to the invisible target during the first acquisition trial for each of the three groups. A one-way between-groups ANOVA conducted on these data detected a significant main effect of group $[F(2,41)=5.17]$. Post hoc comparisons using Fisher's least significant difference (LSD) procedure detected a significant difference between the mean latency of the participants in the control group and that of the participants in Group LL-A, a significant difference between the mean latency of the participants in the control group and that of the participants in Group LL-B, and no significant difference between the mean latency of the participants in Group LL-A and that of the participants in Group LL-B.

These data suggest that, after a latent learning training phase, the participants in Groups LL-A and LL-B had sufficient experience within the virtual environment to develop more efficient search strategies (i.e., plans for movement within the C-G Arena) than the participants in the control group. The data further suggest that the latent learning training phase of the participants in Group LL-A, during which they were exposed to the same room they would search during the acquisition trials, did not help them find the target more rapidly than the participants in Group LL-B, who had not been previously exposed to that room.

Table 3 also presents the mean latency to the invisible target during the relocation trial for each of the three groups. A one-way between-groups ANOVA conducted on these data detected no main effect of group $[F(2,41)<$ 1]. This analysis suggests that the preacquisition exposure of the participants in Group LL-A to the layout of the C-G experimental room did not help them relocate the target more rapidly than the participants in the other groups.

\section{SUMMARY OF RESULTS OF EXPERIMENTS 1-3}

Examinations of the individual acquisition data in each of the three experiments presented above revealed that the group means presented in Tables 2 and 3 , and the data analyses presented above, fairly represented individual performance. Additionally, in all three experiments described above, the data patterns produced by the participants across acquisition trials and on the probe trial were as expected, given the learning curves typically produced by participants completing the C-G Arena task (see Jacobs et al., 1997; Jacobs et al., 1998). That is, the participants in each of the experimental and control groups (1) acquired and remembered the location of the invisible target, (2) moved to that location with increasing efficiency across acquisition trials, and (3) searched the target quadrant more carefully than they searched the other quadrants of the arena during the probe trial.

The data from Experiments 1 and 2 suggest, respectively, that humans learn the location of an invisible target in a computer-generated space by (1) being exposed to a view of the external environment from the location of that target and (2) observing another move toward the target and find that target. The data further suggest that, when 
Table 4

C-G Arena Trial Parameters of Experiment 4 (Comparison)

\begin{tabular}{llllll}
\hline & \multicolumn{3}{c}{ Training Phase } & & \\
\cline { 2 - 4 } \multicolumn{1}{c}{ Parameter } & $\begin{array}{c}\text { Placement } \\
\text { Learning }\end{array}$ & $\begin{array}{c}\text { Observational } \\
\text { Learning }\end{array}$ & $\begin{array}{c}\text { Latent } \\
\text { Learning }\end{array}$ & Acquisition Phase & Probe Trial \\
\hline Number of trials & 4 & 4 & 4 & 6 & 1 \\
Sequence of start locations* & - & E, S, W, N & S, N, W, E & E, S, W, N, E, S & Random \\
Target condition & Visible & Invisible & Absent & Invisible & Absent \\
Target location & NW quadrant & NW quadrant & - & NW quadrant & - \\
Time limit & $30 \mathrm{sec}$ & $45 \mathrm{sec}$ & $45 \mathrm{sec}$ & $180 \mathrm{sec}$ & $90 \mathrm{sec}$ \\
\hline
\end{tabular}

*The $\mathrm{E}$ (East) starting location was near the middle of the East wall of the arena, the $\mathrm{S}$ (South) starting location was near the middle of the South wall, and so on. Each start location (including the randomly determined one featured in the probe trial) faced and was within 2 units of the closest part of the arena wall. The sequence of starting locations was pseudorandomly determined so that successive trials never began at the same location. Each participant received an identical sequence of starting locations. The participants began each trial on the target, facing, across the four trials, South, West, North, and East, respectively.

later required to find that target, individuals who have received such training remember the location of the target and move more directly to it than do naive individuals. These data are consistent with similar investigations of rats in the Morris water maze (see, e.g., Keith \& McVety, 1988; Sutherland \& Linggard, 1982) and of animals in real-world space (see, e.g., Bednekoff \& Balda, 1996; Darby \& Riopelle, 1959; Heyes \& Dawson, 1990; Heyes, Jaldow, \& Dawson, 1994; Zentall, Sutton, \& Sherburne, 1996). The data are also consistent with predictions made by cognitive mapping theory (O'Keefe \& Nadel, 1978). Experiment 3 failed to detect, in humans in a virtual environment, the classic latent learning effect revealed by investigations of rats in dry-land mazes (see, e.g., Blodgett, 1929; Mackintosh, 1974; Munn, 1950; Tolman, 1938,1948 ) and predicted by cognitive mapping theory (O'Keefe \& Nadel, 1978, p. 263). This failure may be due to several factors, none of which was addressed by the design of the experiment in question. A full discussion of the implications of the latter data is not suited for this forum; we are currently designing studies to examine variables that may predict and control the emergence of the latent learning effect in human spatial navigation tasks. ${ }^{7}$

\section{EXPERIMENT 4 Direct Comparison of the Three Training Procedures}

The purpose of Experiment 4 was to directly compare the efficacy of the three training procedures described above. As noted previously, the C-G Arena software used in this experiment was a revised version of that used in Experiments 1-3. Nonetheless, the participants' objective experience of the $\mathrm{C}-\mathrm{G}$ Arena task was consistent across experiments.

\section{Method}

Participants. Fifty-seven undergraduate students (23 males and 34 females), between 18 and 28 years of age $(M=20.00$ years $)$, served as participants. Each participant was randomly assigned to a placement learning group $(n=15)$, an observational learning group $(n=12)$, a latent learning group $(n=16)$, or a control group $(n=14)$.

Procedure. The experiment consisted of four phases: a training phase, a preacquisition ART phase, an acquisition and probe phase, and a postacquisition ART phase.

Training phase. The participants in the placement learning group received a series of placement learning trials formally identical to those described in Experiment 1.

The participants in the observational learning group received a series of observational learning trials similar to those described in Experiment 2, differing only in this respect: A "playback" feature of the revised C-G Arena software was used during the trials. Thus, each participant in the observational learning group watched the PC monitor replay a series of acquisition trials, during which an experimenter located the target and rotated on it before exiting the $\mathrm{C}-\mathrm{G}$ experimental room. Because each participant thus received precisely the same training, experimental control over observational learning was superior to that in Experiment 2.

The participants in the latent learning group received a series of latent learning trials formally identical to those received by Group LL-A in Experiment 3.

Critical parameters for the placement learning, observational learning, and latent learning trials are shown in Table 4.

Preacquisition ART phase. Immediately following their respective training phases, the participants in the placement learning, observational learning, and latent learning groups were administered an arena reconstitution task (ART). This task requires participants to reconstitute the $\mathrm{C}-\mathrm{G}$ experimental room by appropriately placing icons representing the four walls of the room, the objects on those walls, and the target onto a sheet of paper (see Skelton, Bukach, Laurance, Thomas, \& Jacobs, 2000; Thomas et al., 1999). The ART thus measures how accurately participants (1) reconstitute the spatial relationships among arena walls (a relational measure), (2) arrange the objects on those walls (a grouping measure), and (3) place the target in its appropriate location (a target placement measure).

The task is initiated when an experimenter reveals to the participant a sheet of paper on which four equal-sized rectangular areas are drawn around a circle. A blank square is drawn within each quadrant of the circle.

The relational stage of the task begins with the experimenter showing the participant four rectangular pieces of laminated cardboard, each representing one of the walls of the $\mathrm{C}-\mathrm{G}$ experimental room. The participant is told to place the icons into the rectangular areas on the sheet of paper in the same way they were arranged in the experimental room.

The grouping stage of the task begins with the experimenter presenting several smaller pieces of laminated cardboard, each repre- 
Table 5

Mean Scores (Percentages) on Preacquisition and Postacquisition ART of Experiment 4 (Comparison)

\begin{tabular}{lcccccccc}
\hline & \multicolumn{4}{c}{ Preacquisition ART } & & \multicolumn{3}{c}{ Postacquisition ART } \\
\cline { 2 - 4 } \multicolumn{1}{c}{ Group } & $n$ & Relational & Grouping & Target & & Relational & Grouping & Target \\
\hline Control & 14 & - & - & - & & 86.73 & 89.29 & 67.86 \\
Placement learning & 15 & 91.43 & 88.33 & 46.67 & & 98.10 & 100 & 73.33 \\
Observational learning & 12 & 94.05 & 95.83 & 91.67 & & 100 & 100 & 91.67 \\
Latent learning & 16 & 91.07 & 100 & $-*$ & 93.75 & 98.44 & 75.00 \\
\hline
\end{tabular}

*The participants in the latent learning group were not administered the target placement stage of the preacquisition ART because no target was present in the C-G experimental room during their training trials.

senting one of the objects on the walls of the $\mathrm{C}-\mathrm{G}$ experimental room. The participant is told to place the icons onto the cardboard "walls" in the same way they were arranged in the experimental room.

The target placement stage of the task begins with the experimenter presenting one small blue laminated cardboard square, representing the target in the experimental room. The participant is told that each blank square within the circle on the paper represents a potential location for the target and is told to place the cardboard piece into the appropriate square. (Please visit http://w3.arizona.edu/ $\sim \arg /$ papers/place $3 . h t m l$ for a copy of the ART instructions given to participants, a diagram showing how the task is presented to participants, and a table depicting the task's scoring rubric.)

The participants in the placement learning and observational learning groups were administered the entire ART. The participants in the latent learning group were administered only the relational and grouping portions of the task.

Acquisition and probe phase. After completing the ART, the participants in the placement learning, observational learning, and latent learning groups received a series of acquisition trials and a probe trial. During the acquisition trials, an invisible target was located in the same place the target had been located during the training phases for the participants in the placement learning and observational learning groups. The participants in the control group received only an identical series of acquisition trials and an identical probe trial. Critical parameters for the acquisition trials and probe trial are shown in Table 4.

Postacquisition ART phase. Immediately following the probe trial, the participants in all four groups were administered all three stages of the ART.

\section{Results and Discussion}

Table 5 presents the mean scores (in percentages) of the participants in the placement learning, observational learning, and latent learning groups on the preacquisi- tion ART. On each of the components, scores were not normally distributed; thus, we used nonparametric tests to analyze the data. Kruskal-Wallis one-way ANOVAs detected no significant main effect of group on either the relational measure or the grouping measure. A MannWhitney $U$ test detected a significant difference between the placement learning group and the observational learning group on the target placement measure $(U=34.50)$.

Table 6 presents the mean latency to the invisible target during the first acquisition trial for each of the four groups. A one-way ANOVA conducted on these data detected a significant main effect of group $[F(3,53)=3.35]$. Post hoc comparisons using Tukey's HSD test detected only one statistically significant difference: between the mean latency of the participants in the observational learning group and that of the participants in the control group.

Taken together, these data suggest that, although the three training procedures were equally effective in teaching the participants the layout of the $\mathrm{C}-\mathrm{G}$ experimental room, the observational learning procedure was most effective (relative to naive participants) in teaching the participants the location of the invisible target (relative to distal cues) within the room.

Data from the remainder of the acquisition trials, the probe trial (see Table 6), and the postacquisition ART (see Table 5) indicate that the participants in each of the four groups (1) acquired and remembered the location of the invisible target, (2) moved to that location with increasing efficiency across acquisition trials, (3) searched the target

Table 6

Time to Invisible Target on First Acquisition Trial and Dwell Time on Probe Trial of Experiment 4 (Comparison)

\begin{tabular}{|c|c|c|c|c|}
\hline \multirow[b]{2}{*}{ Group } & \multicolumn{2}{|c|}{$\begin{array}{l}\text { Time to Target: } \\
\text { First Acquisition Trial }\end{array}$} & \multicolumn{2}{|c|}{$\begin{array}{l}\text { Dwell Time in Target } \\
\text { Quadrant: Probe Trial* }\end{array}$} \\
\hline & $M$ & SEM & $M$ & $S E M$ \\
\hline Control & 94.64 & 17.41 & 53.05 & 5.02 \\
\hline Placement learning & 83.88 & 13.46 & 42.68 & 5.12 \\
\hline Observational learning & 41.40 & 9.94 & 52.52 & 7.38 \\
\hline Latent learning & 53.91 & 10.65 & 48.27 & 4.87 \\
\hline
\end{tabular}

Note-The measurements of time to target and of dwell time (time spent in a particular arena quadrant) are in seconds. *In this case, the maximum dwell time (time spent in a particular arena quadrant $)=60$, because the probe trial had a 60 -sec time limit. 
Table 7

C-G Arena Trial Parameters in Experiment 5 (fMRI)

\begin{tabular}{|c|c|c|c|c|c|}
\hline \multirow[b]{3}{*}{ Parameter } & \multicolumn{2}{|c|}{ fMRI Training Phase } & \multirow{2}{*}{\multicolumn{3}{|c|}{ C-G Arena Testing Phase }} \\
\hline & \multirow{2}{*}{$\begin{array}{l}\text { Observational Learning: } \\
\text { Visible Target Location }\end{array}$} & \multirow{2}{*}{$\begin{array}{l}\text { Observational Learning: } \\
\text { Place Acquisition }\end{array}$} & & & \\
\hline & & & Acquisition Trials & Probe Trial & Visible Target Trials \\
\hline Number of trials & 4 & 4 & 6 & 1 & 7 \\
\hline Sequence of start locations & $\mathrm{N}, \mathrm{S}, \mathrm{W}, \mathrm{N}$ & $\mathrm{E}, \mathrm{S}, \mathrm{W}, \mathrm{N}$ & E, S, N, E, S, W & Random & $\mathrm{E}, \mathrm{N}, \mathrm{W}, \mathrm{E}, \mathrm{S}, \mathrm{W}, \mathrm{E}$ \\
\hline Target condition & Visible & Invisible & Invisible & Absent & Visible \\
\hline Target location sequence* & NE, NW, SW, SE & NW quadrant & NW quadrant & - & $\mathrm{C}, \mathrm{NE}, \mathrm{NW}, \mathrm{SW}, \mathrm{SE}, \mathrm{NE}, \mathrm{C}$ \\
\hline Time limit & $30 \mathrm{sec}$ & $30 \mathrm{sec}$ & $180 \mathrm{sec}$ & $120 \mathrm{sec}$ & $120 \mathrm{sec}$ \\
\hline
\end{tabular}

quadrant (NW) more carefully than they searched the other quadrants of the arena during the probe trial, and (4) accurately reconstituted the C-G experimental room (including the location of the invisible target) using twodimensional cardboard icons. Data analyses detected no significant group differences on the final acquisition trial, the probe trial, or the postacquisition ART.

\section{EXPERIMENT 5 Functional Neuroimaging of Observational Learning}

The purpose of Experiment 5 was to demonstrate the use of a C-G Arena observational learning procedure in a functional magnetic resonance imaging (fMRI) protocol.

\section{Method}

Participants. Two male undergraduates (M.F., 22 years old, and D.R., 20 years old) served as participants. These participants were part of a larger sample $(N=15)$ tested in a neuroimaging study of place learning (Hsu, Ryan, Nadel, Thomas, \& Jacobs, 2001). We present data from these 2 participants to illustrate the quality of data one might obtain using this preparation: They provide the maximum contrast within both blood-oxygenati on level dependent (BOLD) signal and behavioral performance measures.

Procedure. The experiment consisted of two phases: an fMRI training phase and a C-G Arena testing phase.

fMRI training phase. While in the MRI machine, the participants received a dynamic first-person view of the C-G Arena through a three-dimensional (3-D) high-resolution head-mounted display (Resonance Technology, Inc., Northridge, CA). The stimuli were grouped into the following three conditions:

1. Place acquisition. The participants received a series of observational learning trials similar to those used in Experiment 2. In this experiment, a videotape showed a series of observational learning trials, during which an experimenter entered the arena, turned to face the location of the target, moved directly toward the location of the invisible target, and then stood on the target and rotated $180^{\circ}$ to $360^{\circ}$ in place. Critical parameters for these trials are shown in Table 7. As can be seen from the table, each trial lasted $30 \mathrm{sec}$ : an average of $11 \mathrm{sec}$ panning toward the approximate location of the target, an average of $7.5 \mathrm{sec} \mathrm{mov-}$ ing toward the target, and an average of $11.5 \mathrm{sec}$ rotating on the target. The waiting room condition was not shown on the videotape.

2. Visible target location. The participants received a series of videotaped trials identical to those in the place acquisition condition, but with these exceptions: The target was always visible, and it changed loca- tions from trial to trial. Critical parameters for these trials are shown in Table 7. As can be seen from the table, each trial lasted $30 \mathrm{sec}$ : an average of $10 \mathrm{sec}$ panning toward the approximate location of the target, an average of $7 \mathrm{sec}$ moving toward the target, and an average of $13 \mathrm{sec}$ rotating on the target.

3. Kaleidoscope. The participants received a series of videotaped presentations of the Kaleidoscope screensaver (Syntrillium Software Corp., Phoenix, AZ). These pseudorandomly generated kaleidoscopic images contained similar speed of movement and mixture of color to those found in the C-G Arena but lacked depth cues.

The portion of the videotape analyzed and reported here was $528 \mathrm{sec}$ long and consisted of four stimulus blocks, with each block consisting of this sequence of conditions: place acquisition-kaleidoscopevisible target location-kaleidoscope. Additionally, in this report, we concentrate exclusively on data obtained from the hippocampal formation.

$C$-G Arena testing phase. After completing the scanning portion of the experiment, the participants were removed from the magnet and placed in a reclining position on a hospital bed. They were then administered a C-G Arena task via the same head-mounted display used in the scanner. The task comprised a series of acquisition trials, a probe trial, and a series of visible target trials. During the acquisition trials, an invisible target was located in the same place the invisible target had been located during the fMRI training phase. The visible target trials were formally identical to those observed by the participant during the fMRI training phase. Critical parameters for the acquisition trials, probe trial, and visible target trials are shown in Table 7.

fMRI data acquisition and analysis. Magnetic resonance images were acquired using a 1.5 Tesla GE Signa System (General Electric, Milwaukee, WI). A birdcage head coil was used for RF transmission and reception. Scans consisted of 23 slices, covering brain regions from the prefrontal cortex to the occipital lobe. Coronal images were acquired in oblique spirals perpendicular to the long axis of the hippocampus (slices $=23$; thickness $=6 \mathrm{~mm}$; skip $=$ $0 \mathrm{~mm} ; \mathrm{TR}=3,000 \mathrm{msec}$ ). The $\mathrm{fMRI}$ data were acquired during one scan lasting $531 \mathrm{sec}$ (177 reps).

The fMRI data were "cleaned" in three ways before analysis: (1) After functional image acquisition, signals were reregistered to correct for movement-related artifacts in 2-D; (2) after signal reregistration, functional images were reconstructed into functional data sets; (3) after functional image reconstruction, a Fourier 3-D transform volume reregistration was run to correct movement-related artifacts in 3-D.

Analyses of the fMRI data were performed on a Sun Solaris 4 workstation running the MCW AFNI package (Cox \& Hyde, 1997). Functional MRI data were correlated with an ideal model of activation. Thresholds for the activity maps were set at $p=.01$. Only 
Place Acquisition - Kaleidoscope
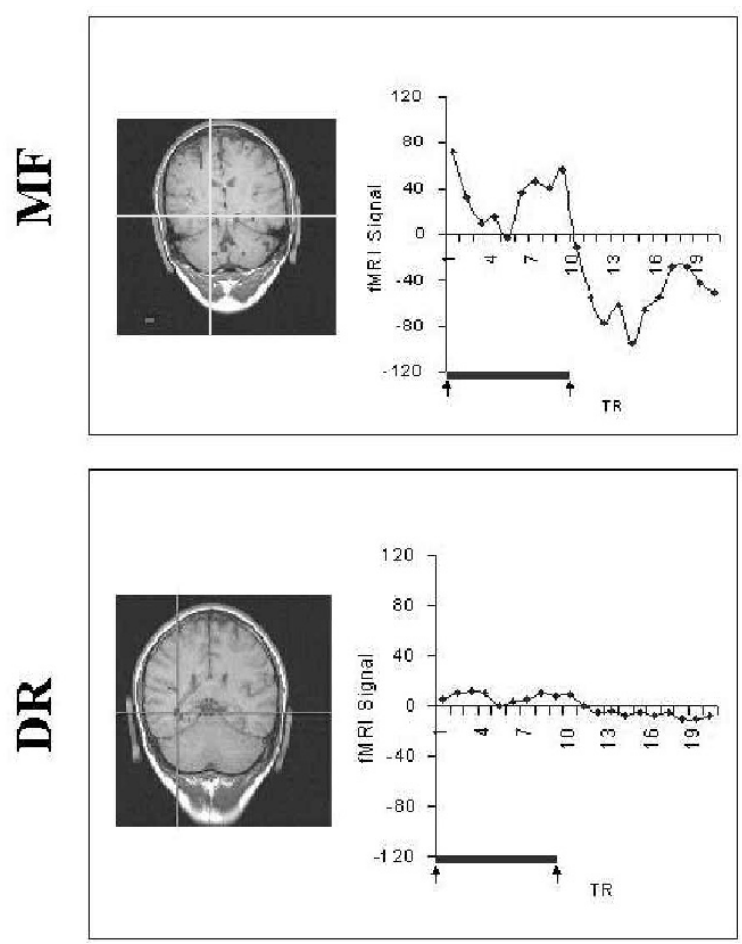

Visible Target Location - Kaleidoscope
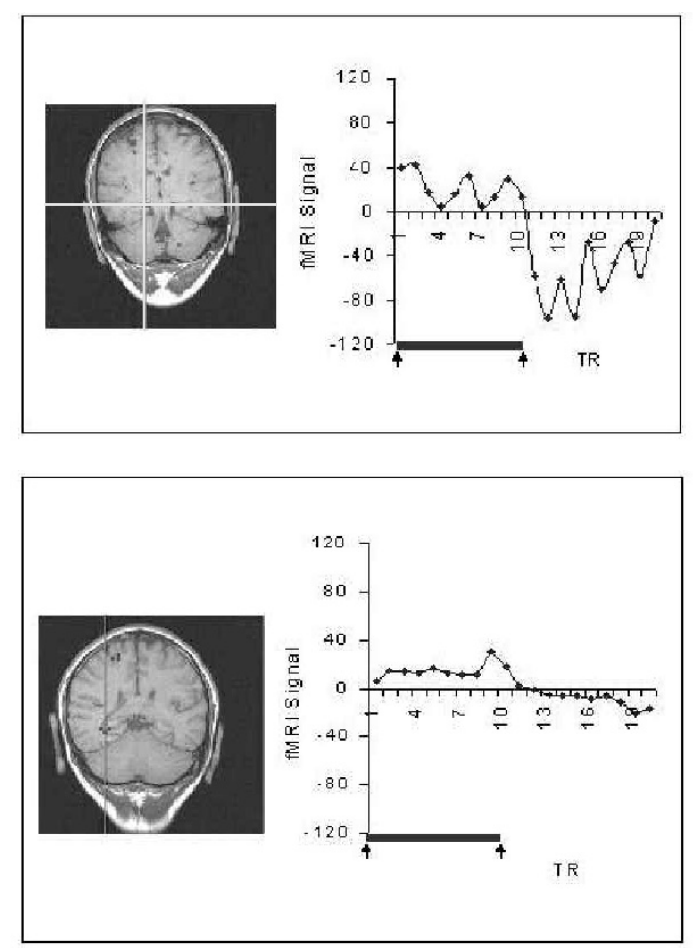

Figure 2. Right hippocampal activity in Participants M.F. and D.R. for the place acquisition - kaleidoscope model and the visible target location - kaleidoscope model in Experiment 5. The crosshairs in each image are trained on the right hippocampal region. On the graphs, the $y$-axis indicates adjusted trial-averaged fMRI signal, the $x$-axis indicates time (TR $=$ repetition time; $1 \mathrm{TR}=3,000 \mathrm{msec}$ ), and the black bar bounded by two arrows indicates the duration of stimulus onset. Thus, in each graph, the stimulus (the target) was present for $10 \mathrm{TR}(30 \mathrm{sec})$.

clusters of activation greater than $120 \mu \mathrm{l}$ (3 voxels) were retained and subjected to further analysis.

We hypothesized that activation revealed by comparing experimental conditions against control conditions represents heightened neuronal processing during experimental conditions. Two models were used to test this hypothesis, each comparing an experimental condition against the control condition: The place acquisition kaleidoscope model subtracted activation observed on trials during the kaleidoscope condition from activation observed on trials during the place acquisition condition; the visible target location kaleidoscope model subtracted activation observed on trials during the kaleidoscope condition from activation observed on trials during the visible target location condition.

After the clusters of activation were isolated, the MR signals for entire time series were extracted and averaged to determine the mean response during each of the three stimulus conditions.

\section{Results}

fMRI. Participants M.F. and D.R. both showed clusters of activation in the right posterior hippocampal region (M.F. volume $=338 \mu$ l; D.R. volume $=422 \mu$ l) during the place acquisition condition. Figure 2 presents a slice showing the location of these clusters for the place acquisition - kaleidoscope model and the visible target location - kaleidoscope model. ${ }^{8}$ The figure shows that activation in M.F. was especially intense, relative to activation during the kaleidoscope condition, during the final
$15 \mathrm{sec}(5 \mathrm{TRs})$ of the place acquisition condition; over that time, the videotape provided the participant with a full view of the $\mathrm{C}-\mathrm{G}$ experimental room from the vantage point of the invisible target. In contrast, activation in D.R. was never as intense.

C-G Arena. Figure 3 presents the mean latency to find the target on the visible target trials and acquisition trials for Participants M.F. and D.R. A one-way ANOVA conducted on the visible trials data detected no significant differences between the time the participants took to locate and stand on the visible target. A similar analysis conducted on the acquisition trials data, however, detected a significant difference between the time the participants took to locate and stand on the invisible target $[F(1,10)=23.56]$. Figure 4 illustrates search paths for each participant on the first visible target trial and on two of the acquisition trials. Clearly, the data analysis presented above fairly represents each participant's performance on the C-G Arena task.

\section{Discussion}

The data presented above suggest that place learning and memory are related to activation in the right hippocampal formation. In the case in which the target location was learned (Participant M.F.), there was activation 


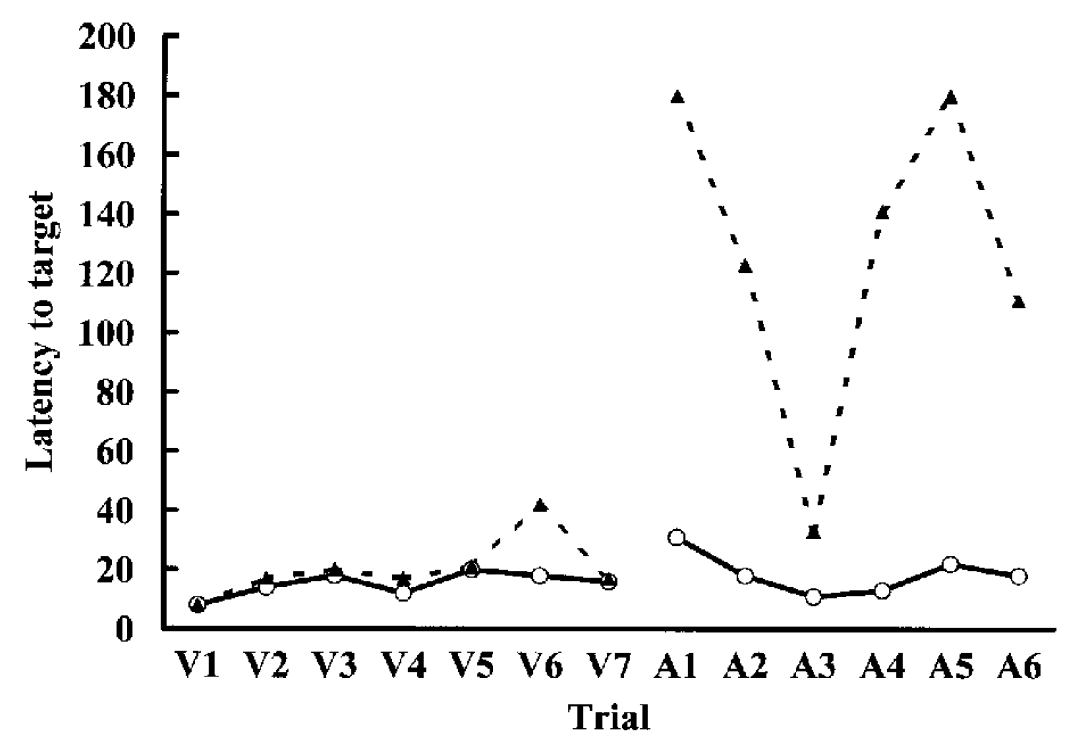

Figure 3. The mean time in seconds that Participants M.F. and D.R. required in order to find the target on the seven visible target trials and on the six acquisition trials administered in Experiment 5. The solid lines represent the performance of Participant M.F.; the dashed lines represent the performance of Participant D.R.

of greater intensity than in the case in which the target location was not learned (Participant D.R.). Furthermore, the activation of the hippocampus centers on periods where the video display is panning approximately $360^{\circ}$ to provide a full view of the room (i.e., during the first and last $10 \mathrm{sec}$ of each trial). This data pattern is consistent with cognitive mapping theory: Spatial relationships between distal cues and the invisible target are best established when the participant is provided a full view of the virtual environment. Although data from only 2 participants are presented here, preliminary data from the remainder of the sample support these results (Baker, Hsu, Ryan, Nadel, \& Jacobs, 1998; Hsu et al., 2001). The present results are also generally concordant with data from other laboratories (Maguire et al., 1998; Maguire, Frackowiak, \& Frith, 1997).

\section{EXPERIMENT 6 \\ The Effects of Temporal Lobe Lesions on C-G Arena Performance}

\section{Method}

Two females from the University of Arizona community (A.W., 52 years old, and M.H., 41 years old) served as participants. Both participants had experienced right temporal lobectomies to relieve intractable epilepsy, A.W. in 1995 and M.H. in 1994. Surgery was successful in both cases. Demographic data for both participants are presented in Table 8 .

The participants experienced a training phase consisting of series of demonstration trials in a C-G experimental room identical to that presented to the participants in Group LL-B of Experiment 3. During those demonstration trials, an experimenter used a joystick to move in the experimental room and to locate a target. While doing so, the experimenter familiarized the participant with the formal as- pects of the C-G Arena and with the task she would be asked to accomplish.

Immediately following this training phase, the participants received, in this order, (1) two practice trials, featuring a visible target in the C-G experimental room, (2) a series of acquisition trials, (3) a probe trial, and (4) a final trial, which was identical to the first practice trial. Critical parameters for the trials are shown in Table 9.

\section{Results and Discussion}

Figure 5 presents the mean latency to find the target on the practice, acquisition, and final trials for Participants A.W. and M.H., and Figure 6 illustrates search paths for each participant on the first practice trial and on two of the acquisition trials. The participants' performance on the practice trials and on the final trial compares favorably with that of age-group peers with no neurological history (see Thomas et al., 1999) — that is, these data suggest that Participants A.W. and M.H. had little difficulty moving toward and standing on a visible target in the $\mathrm{C}-\mathrm{G}$ experimental room. In contrast, the acquisition curves and acquisition trial search paths demonstrated by A.W. and M.H. are clearly different from those demonstrated by undergraduate students with no neurological history (see Jacobs et al., 1997; Jacobs et al., 1998) and from those demonstrated by age-group peers with no neurological history (see Thomas et al., 1999) — that is, data from the acquisition trials suggest that A.W. and M.H. had difficulty learning and remembering the location of an invisible target in the $\mathrm{C}-\mathrm{G}$ experimental room.

Data from the probe trial and from the postacquisition ART (see Table 10) support the notion that both participants learned the location of the invisible target suboptimally and that Participant A.W. learned the layout of the 


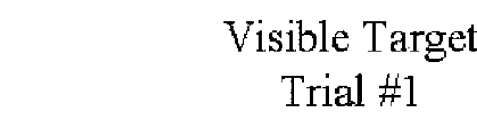

MF
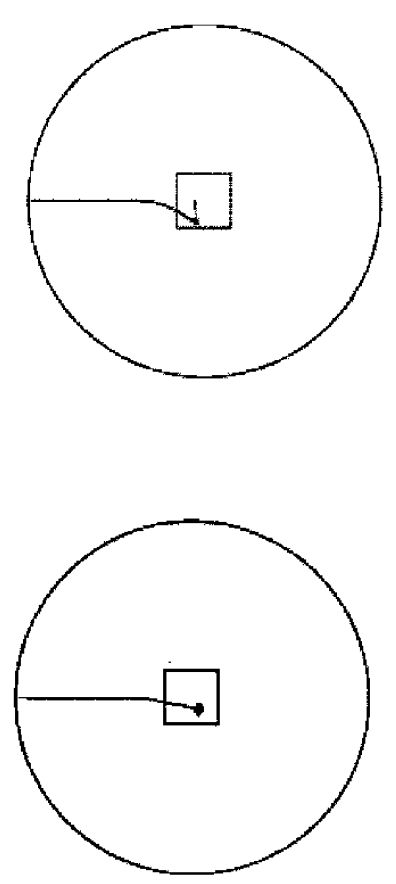

Acquisition Trial \#4
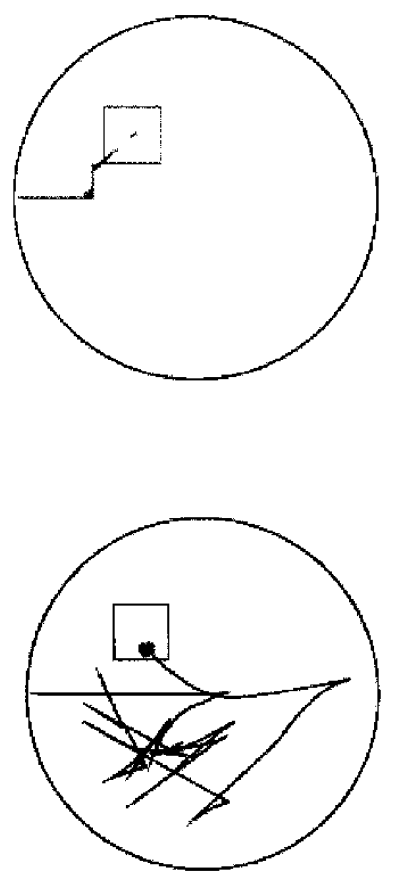

Acquisition

Trial \#6
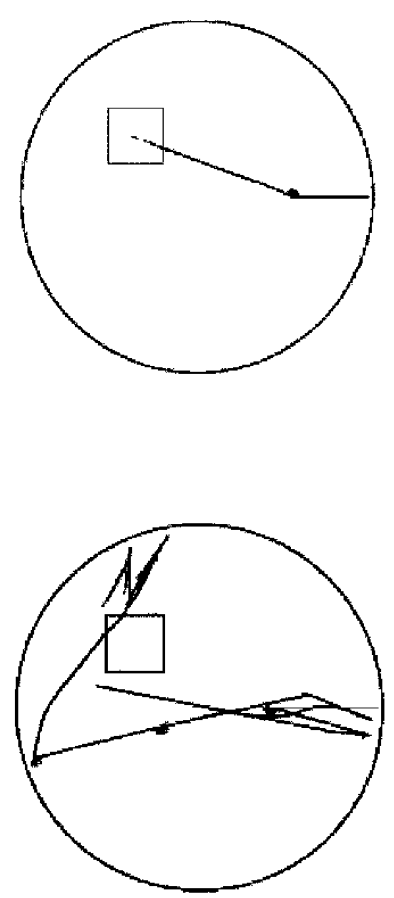

Figure 4. An aerial view of the search paths taken by Participants M.F. and D.R. on the first visible target trial and on the fourth and sixth acquisition trials in Experiment 5.

arena suboptimally. In summary, then, these preliminary data support the notion that right hippocampal function is crucial for spatial learning and memory. They are thus congruent with the data presented in Experiment 5 above and with data from other laboratories (see, e.g., Abrahams, Pickering, Polkey, \& Morris, 1997; Bohbot et al., 1998; Maguire et al., 1998; Maguire et al., 1997). Perhaps more significantly, these data illustrate two potential uses of the C-G Arena and the ART in neuropsychologicalevaluation (see also Skelton et al., 2000).

\section{GENERAL DISCUSSION}

The experiments described above demonstrated three different training procedures for participants in a VE spatial navigation task, the C-G Arena. In Experiment 1, the participants who received a series of placement learning trials moved more directly and efficiently to the location of an invisible target than did the control participants who had received no training. In Experiment 2, the participants who received a series of observational learning

Table 8

Demographic Data for the Participants in Experiment 6 (Temporal Lobe Lesions)

\begin{tabular}{|c|c|c|}
\hline & \multicolumn{2}{|c|}{ Participant } \\
\hline & A.W. & M.H. \\
\hline Handedness & Right & Right \\
\hline Marital status & Married & Married \\
\hline Years of education & 13 & 13 \\
\hline Employment status & Unemployed & Unemployed \\
\hline Sensory-perceptual status & Wears eyeglasses & Wears eyeglasses \\
\hline Other neurological history & Nonsignificant & Nonsignificant \\
\hline Recent physical health history & May 1998: Successful breast cancer surgery & No significant issues \\
\hline Mental health history & 1995: Diagnosed "paranoid schizophrenic" & Nonsignificant \\
\hline Medications at time of testing & Tegretol, Resperdal, Cycrin, estradiol & Tegretol, Provera, estrogen patch \\
\hline Substance use history & Nonsignificant & Nonsignificant \\
\hline
\end{tabular}


Table 9

C-G Arena Trial Parameters in Experiment 6 (Temporal Lobe Lesions)

\begin{tabular}{|c|c|c|c|c|c|c|}
\hline \multirow[b]{2}{*}{ Parameter } & \multicolumn{3}{|c|}{ Demonstration Phase } & \multicolumn{3}{|c|}{ Testing Phase } \\
\hline & Trial 1 & Trial 2 & Practice Trials & Acquisition Trials & Probe Trial & Final Trial \\
\hline Number of trials & 1 & 1 & 2 & 6 & 1 & 1 \\
\hline Sequence of start locations & $\mathrm{S}$ & $\mathrm{N}$ & $\mathrm{E}, \mathrm{W}$ & $S, E, N, W, E, S$ & Random & $\mathrm{E}$ \\
\hline Target condition & Visible & Invisible & Visible & Invisible & Absent & Visible \\
\hline Target location & $\mathrm{NE}$ & SW & C, SE & NW & - & $\mathrm{C}$ \\
\hline Time limit & $300 \mathrm{sec}$ & $300 \mathrm{sec}$ & $180 \mathrm{sec}$ & $180 \mathrm{sec}$ & $90 \mathrm{sec}$ & $180 \mathrm{sec}$ \\
\hline
\end{tabular}

trials moved more directly and efficiently to the location of an invisible target than did the control participants who had received no training. In Experiment 3, the participants who received a series of latent learning trials showed few navigational advantages over the control participants who had received no training. Experiment 4 demonstrated that the observational learning procedure is the most effective of the three training procedures in teaching participants about the layout of the virtual environment and about the location of the target within that environment.

The use of a companion task to the C-G Arena, the ART, was also described above. Experiments 4, 5, and 6 demonstrated that the ART provides data congruent with those gathered from the C-G Arena task, thus establishing convergent evidence of place learning in humans. The ART may also provide a measure of some different aspect of learning and memory (e.g., object memory or memory for environmental cues). Psychometric studies of the ART are currently underway in our laboratory.

Cognitive mapping theory (Nadel, 1991; O'Keefe \& Nadel, 1978) guided the design and the data interpretation in each of the four experiments described above. This theory states that an organism successfully navigates through and within an environment using a previously formed cognitive map of that environment. Cognitive maps of an environment, consisting of information about specific objects and spatial relations among them, are formed when an organism observes and explores an environment. More specifically, observation and exploration of an environment allow an organism to (1) acquire mental representations of spatial relations among stimuli in the environment, (2) form a cognitive map of the

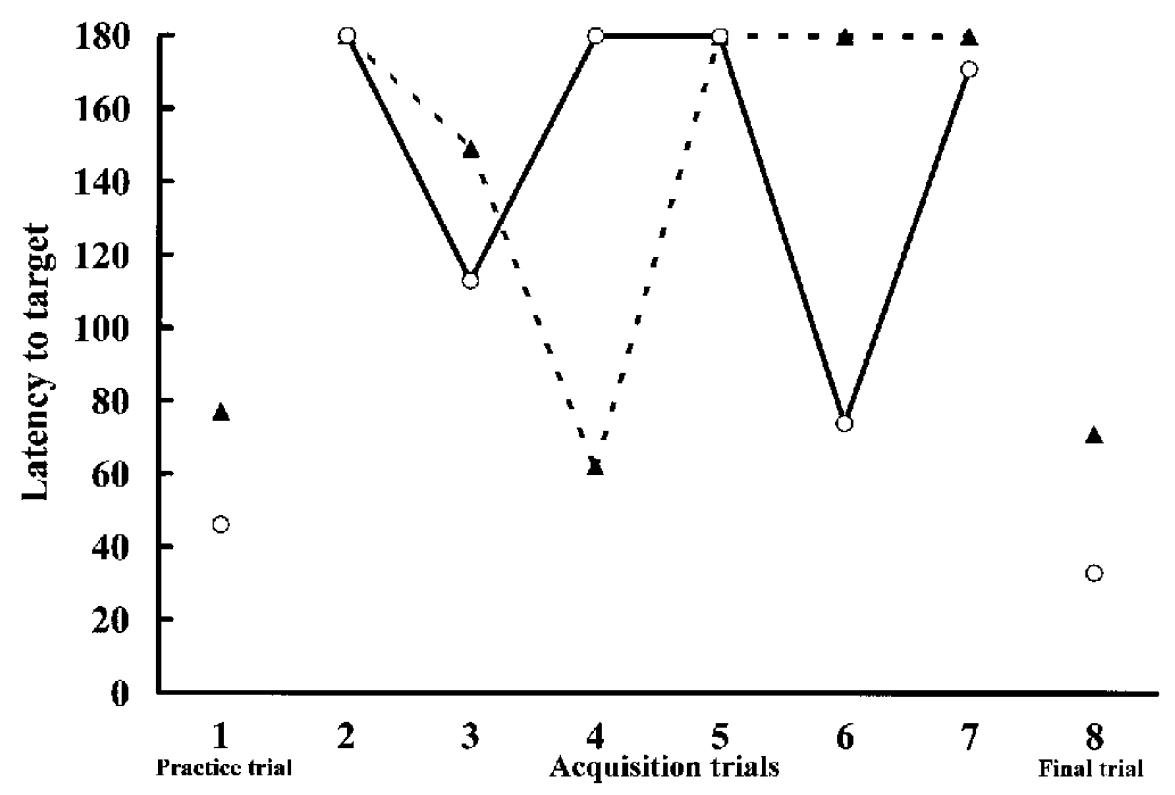

Figure 5. The mean time in seconds that Participants A.W. and M.H. required in order to find the target on the first practice trial, the six acquisition trials, and the final trial administered in Experiment 6. (Data from the second practice trial are unavailable because of a software error in recording data.) The dashed lines and the triangle markers represent the performance of Participant A.W.; the solid lines and the circle markers represent the performance of Participant M.H. 

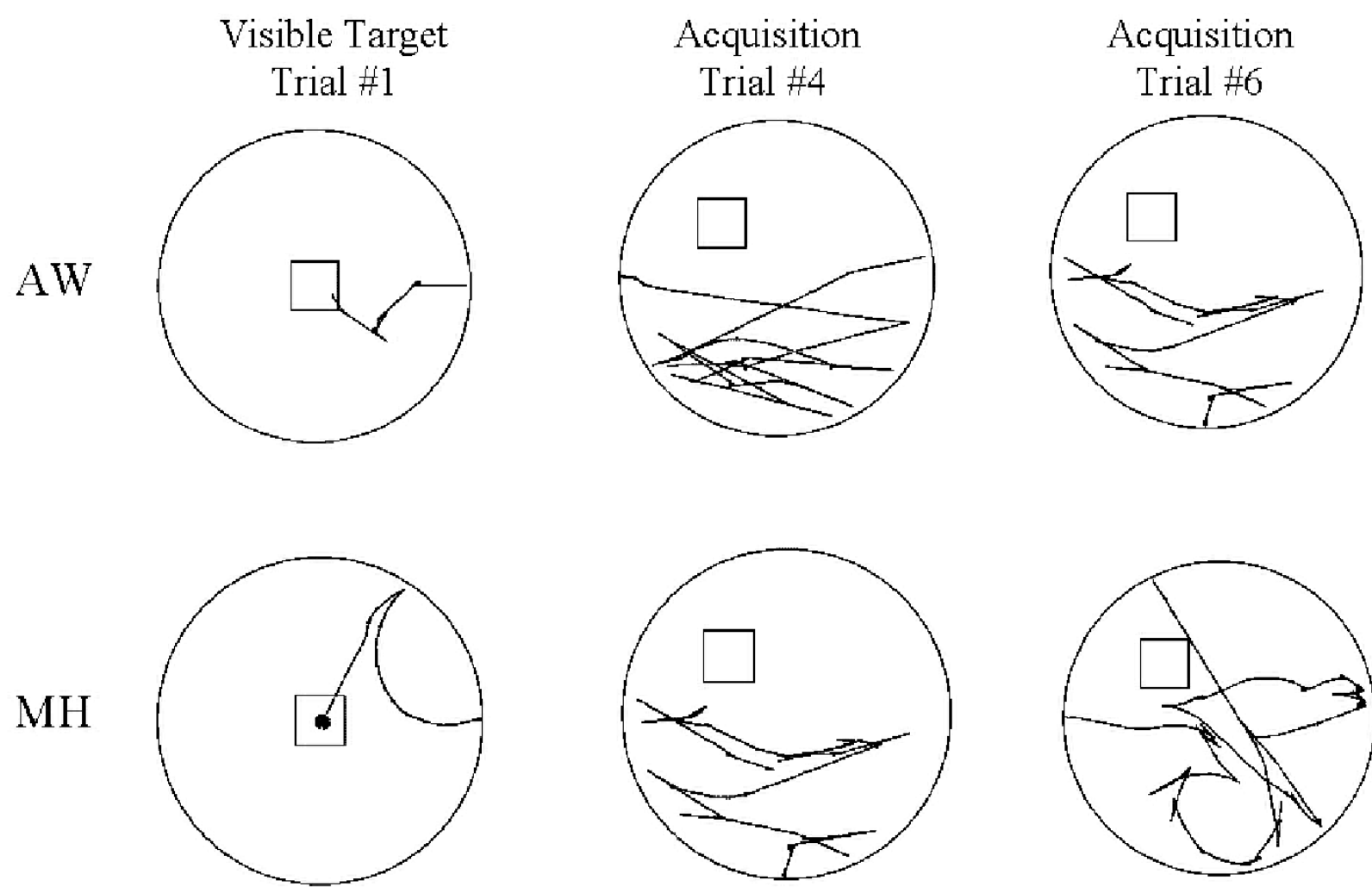

Figure 6. An aerial view of the search paths taken by Participants A.W. and M.H. on the first visible target trial and on the fourth and sixth acquisition trials in Experiment 6. The deficits shown by Participants A.W. and M.H. on the C-G Arena task are made particularly clear when one compares their search paths on the acquisition trials with those of Participants M.F. and D.R. (see Figure 4 of the present paper) and with those of a neurologically intact individual of approximately the same age (see Figure 9 of Thomas et al., 1999).

environment based on those mental representations, and (3) use that cognitive map to generate novel search strategies within the environment.

Within the context of cognitive mapping theory, the data presented above indicate that, in computer-generated space, humans acquire representations of distal cues, and the spatial relations among them, through the training procedures of placement learning, observational learning, and, perhaps, latent learning. These representations are retained as a cognitive map of the computer-generated environment, so that upon reexposure to the environment (the acquisition trials), participants retrieve the appropriate map (or fragment of a map). They then use this information to establish their location, and the location of the invisible target, in the environment. Using these two locations as references, motor movements that produce action leading from the current location to the target location are planned and executed.

The success of the placement learning and observational learning training procedures in producing a cognitive map is of interest to those attempting to build theoretical models of spatial learning and memory. For example, both cognitive mapping theory (O'Keefe \& Nadel, 1978, pp. 93-94) and path integration theory (e.g., McNaughton, 1989; McNaughton et al., 1996) argue that a motor set (defined as, at the least, a "preparedness for movement"; see McNaughton et al., 1996, p. 179) is essential to the formation of a cognitive map. Both the placement learning and the observational learning train-

Table 10

Dwell Times on Probe Trial and ART Scores of Experiment 6 (Temporal Lobe Lesions)

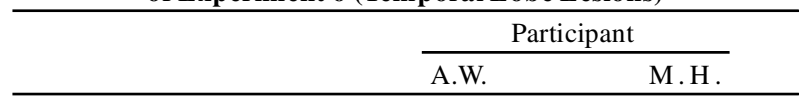

\begin{tabular}{lrr}
\hline & Dwell Time* \\
NW quadrant $\dagger$ & 0 & 64 \\
NE quadrant & 0 & 18 \\
SE quadrant & 43 & 0 \\
SW quadrant & 48 & 9 \\
& ART Component & \\
Relational & $71.43 \%$ & $100 \%$ \\
Grouping & $25.00 \%$ & $100 \%$ \\
Target & $50.00 \%$ & $50.00 \%$
\end{tabular}

*Dwell times are measured in seconds. Thus, in this case, the maximum dwell time (time spent in a particular arena quadrant) $=90$, because the probe trial had a $90-\mathrm{sec}$ time limit. ${ }^{\circ}$ On the acquisition trials, the target was located in this quadrant. 
ing procedures, however, lack the motor component ordinarily associated with spatial information processing (i.e., both preclude the organism from moving through the environment it is required to map), and it is not clear whether the participants in the present experiments had the requisite preparedness for movement. Although it is possible that movement through an environment and toward a target location produces a more robust cognitive map than any of the training procedures described above (see Attree et al., 1996, and Pugnetti et al., 1998, for discussions of active versus passive exploration of virtual environments), the data presented here do indicate that the observational learning procedure, in particular, produces at least a serviceable cognitive map, one that is used as the basis for direct and efficient movement toward the target location in the virtual environment.

Experiments 5 and 6 illustrated two potential applications of the C-G Arena and the ART. Experiment 5 was an example of how the tasks might be used to explore the neural substrates of place learning and spatial navigation in humans. We are currently designing and running studies that use the $\mathrm{C}-\mathrm{G}$ Arena in neuroimaging protocols (see, e.g., Hsu et al., 2001). Experiment 6 was an example of how the tasks might be used in neuropsychological studies of spatial learning and memory. In collaboration with Bauer and his colleagues, we are currently running studies that compare, at various intervals presurgery and postsurgery, C-G Arena and ART performance of patients with right hippocampal lesions with that of patients with left hippocampal lesions (R. M. Bauer, personal communication, September 17, 1999). These studies will, we hope, foreshadow the use of the C-G Arena and ART as tools to assist in the detection of spatial functioning impairments.

Already, C-G Arena software and procedures have been used in studies of fundamental variables affecting human place learning (Jacobs et al., 1997; Jacobs et al., 1998), age-related differences in spatial cognition (Laurance et al., 2001; Thomas et al., 1999), and the effects of traumatic brain injury on spatial learning and memory (Skelton et al., 2000), and in clinical studies (Kállai, Jacobs, Karádi, Thomas, \& Nadel, 2001). Additionally, studies of deficits in place learning and spatial navigation produced by stressful conditions are also underway, as are studies exploring the issue of sex differences in VE spatial navigation and the ontogeny of spatial navigation abilities in humans. In summary, the C-G Arena software possesses programmable flexibility and data-handling capabilities that, coupled with its ease of use and established psychometric properties, make it a valuable tool for researchers in a wide variety of psychological domains.

\section{REFERENCES}

Abrahams, S., Pickering, A., Polkey, C. E., \& Morris, R. G. M. (1997). Spatial memory deficits in patients with unilateral damage to the right hippocampal formation. Neuropsychologia, 35, 11-24.
Arthur, E. J., Hancock, P. A., \& Chrysler, S. T. (1997). The perception of spatial layout in real and virtual worlds. Ergonomics, 40, 69-77.

Astur, R. S., Ortiz, M. L., \& Sutherland, R. J. (1998). A characterization of performance by men and women in a virtual Morris water task: A large and reliable sex difference. Behavioural Brain Research, 93, $185-190$.

Attree, E. A., Brooks, B. M., Rose, F. D., Andrews, T. K., LeadBetTer, A. G., \& Clifford, B. R. (1996). Memory processes and virtual environments: I can't remember what was there, but I can remember how I got there. Implications for people with disabilities. In P. M. Sharkey (Ed.), Proceedings of the 1st European Conference on Disability, Virtual Reality, and Associated Technologies (pp. 117-121). Maidenhead, U.K.: University of Reading.

Aukstakalnis, S., \& Blatner, D. (1992). Silicon mirage: The art and science of virtual reality. Berkeley, CA: Peachpit.

BaKer, C. B., Hsu, M., Ryan, T. L., NAdel, L., \& Jacobs, W. J. (1998, December). Functional neuroimaging of place learning in computergenerated space. Poster presented at the annual meeting of the Robert S. Flinn Foundation Life Science and Biomedical Research Symposium, Tucson, AZ.

BARFIELD, W., \& Furness, T. A., III (Eds.) (1995). Virtual environments and advanced interface design. New York: Oxford University Press.

BedneKoff, P. A., \& BALdA, R. P. (1996). Observational spatial memory in Clark's nutcrackers and Mexican jays. Animal Behaviour, 52, 833-839.

Bliss, J. P., Tidwell, P. D., \& Guest, M. A. (1997). The effectiveness of virtual reality for administering spatial navigation training to firefighters. Presence, 6, 73-86.

BLODGETT, H. C. (1929). The effect of introduction of reward upon the maze learning of rats. University of California Publications in Psychology, 4, 113-134.

Bohbot, V. D., Kalina, M., Stepankova, K., Spackova, N., Petrides, M., \& NAdel, L. (1998). Spatial memory deficits in patients with lesions to the right hippocampus and to the right parahippocampal cortex. Neuropsychologia, 36, 1217-1238.

Brandeis, R, Brandys, Y., \& YehUda, S. (1989). The use of the Morris water maze in the study of memory and learning. International Journal of Neuroscience, 48, 29-69.

Brooks, B. M., McNeil, J. E., Rose, F. D., Greenwood, R. J., Attree, E. A., \& Leadbetter, A. G. (1999). Route learning in a case of amnesia: A preliminary investigation into the efficacy of training in a virtual environment. Neuropsychological Rehabilitation, 9, 63-76.

Cox, R. W., \& HY DE, J. S. (1997). Software tools for analysis and visualization of fMRI data. NMR in Biomedicine, 10, 171-178.

DABRowSKA, J. (1963a). An analysis of reversal learning in relation to the complexity of task in white rats. Acta Biologica Experimentalis, 23, 11-24.

DABRowSKa, J. (1963b). Reversal learning in relation to the pattern of reversal in a three-unit double-choice apparatus. Acta Biologica Experimentalis, 23, 263-266.

Darby, C. L., \& Riopelle A. J. (1959). Observational learning in the rhesus monkey. Journal of Comparative \& Physiological Psychology, 52, 94-98.

Fenton, A. A., Arolfo, M. P., Nerad, L., \& Bureš, J. (1994). Place navigation in the Morris water maze under minimum and redundant extra-maze cue conditions. Behavioral \& Neural Biology, 62, 178-189.

FurNess, T. A., III, \& BARFIELD, W. (1995). Introduction to virtual environments and advanced interface design. In W. Barfield \& T. A. Furness III (Eds.), Virtual environments and advanced interface design (pp. 3-13). New York: Oxford University Press.

Gillner, S., \& Mallot, H. A. (1998). Navigation and acquisition of spatial knowledge in a virtual maze. Journal of Neuroscience, 10, 445-463.

Heyes, C. M., \& Dawson, G. R. (1990). A demonstration of observational learning in rats using a bidirectional control. Quarterly Journal of Experimental Psychology, 42B, 59-71.

HeYes, C. M., JALDOW, E., \& DAwson, G. R. (1994). Imitation in rats: Conditions of occurrence in a bidirectional control procedure. Learning \& Motivation, 25, 276-287. 
Hsu, M., Ryan, T. L., Nadel, L., Thomas, K. G. F., \& Jacobs, W. J. (2001). Functional neuroimaging of place learning in computergenerated space. Manuscript in preparation.

Jacobs, W. J., Laurance, H. E., \& Thomas, K. G. F. (1997). Place learning in virtual space I: Acquisition, overshadowing, and transfer. Learning \& Motivation, 28, 521-541.

Jacobs, W. J., Thomas, K. G. F., Laurance, H. E., \& Nadel, L. (1998). Place learning in virtual space II: Topographical relations as one dimension of stimulus control. Learning \& Motivation, 29, 288-308.

Kállai, J., Jacobs, W. J., Karádi, K., Thomas, K. G. F., \& Nadel, L. (2001). The role of spatial orientation disturbances in maintenance of panic disorder with agoraphobia. Manuscript in preparation.

KeITH, J. R., \& MCVETy, K. M. (1988). Latent place learning in a novel environment and the influences of prior training in rats. Psychobiology, 16, 146-151.

KImble, G. A. (1961). Hilgard and Marquis' conditioning and learning. New York: Appleton-Century-Crofts.

Laurance, H. E., Thomas, K. G. F., Newman, M. C., Kaszniak, A. W., Rubin, S. R., NADEL, L., \& JACOBS, W. J. (2001). Age-related changes in place learning. Manuscript in preparation.

Mackintosh, N. J. (1974). The psychology of animal learning. London: Academic Press.

Maguire, E. A., Burgess, N., Donnett, J. G., Frackowiak, R. S. J., Frith, C. D., \& O'KeEfe, J. (1998). Knowing where and getting there: A human navigation network. Science, 280, 921-924.

Maguire, E. A., Burgess, N., \& O'Keefe, J. (1999). Human spatial navigation: Cognitive maps, sexual dimorphism, and neural substrates. Current Opinion in Neurobiology, 9, 171-177.

Maguire, E. A., Frackowiak, R. S. J., \& Frith, C. D. (1997). Recalling routes around London: Activation of the right hippocampus in taxi drivers. Journal of Neuroscience, 17, 7103-7110.

MAY, M., PÉruch, P., \& SAVOYAnT, A. (1995). Navigating in a virtual environment with map-acquired knowledge: Encoding and alignment effects. Ecological Psychology, 7, 21-36.

McComas, J., Pivik, J., \& Laflamme, M. (1998). Children's transfer of spatial learning from virtual reality to real environments. CyberPsychology \& Behavior, 1, 121-128.

McNaUghton, B. L. (1989). Neuronal mechanisms for spatial computation and information storage. In L. Nadel, L. A. Cooper, P. Culicover, \& R. M. Harnish (Eds.), Neural connections, mental computation (pp. 285-350). Cambridge, MA: MIT Press.

McNaughton, B. L., Barnes, C. A., Gerrard, J. L., Gothard, K., Jung, M. W., Knierim, J. J., Kudrimoti, H., Qin, Y., Skaggs, W. E., Suster, M., \& WeAVer, K. L. (1996). Deciphering the hippocampal polyglot: The hippocampus as a path integration system. Journal of Experimental Biology, 199, 173-185.

MorRIS, R. G. M. (1981). Spatial localization does not require the presence of local cues. Learning \& Motivation, 12, 239-260.

MorRIS, R. G. M. (1984). Developments of a water-maze procedure for studying spatial learning in the rat. Journal of Neuroscience Methods, 11, 47-60.

Muenzinger, K. F., \& ConRad, D. G. (1953). Latent learning observed through negative transfer. Journal of Comparative \& Physiological Psychology, 46, 1-8.

MunN, N. L. (1950). Handbook of psychological research on the rat. Boston: Houghton Mifflin.

NADEL, L. (1991). Hippocampus and space revisited. Hippocampus, 1, 221-229.

Nadel, L., Thomas, K. G. F., Laurance, H. E., Skelton, R., Tal, T., \& JACOBS, W. J. (1998). Human place learning in a computer generated arena. In C. Freksa, C. Habel, \& K. F. Wender (Eds.), Spatial cognition: An interdisciplinaryapproach to representing and processing spatial knowledge (pp. 399-427). Berlin: Springer-Verlag.

O' KeEFE, J., \& NADEL, L. (1978). The hippocampusas a cognitive map. Oxford: Oxford University Press, Clarendon Press.

Péruch, P., Vercher, J.-L., \& Gauthier, G. M. (1995). Acquisition of spatial knowledge through visual exploration of simulated environments. Ecological Psychology, 7, 1-20.

Pimentel, K., \& Teixiera, K. (1995). Virtual reality: Through the new looking glass. Toronto: McGraw-Hill.

Pugnetti, L., Mendozzi, L., Brooks, B. M., Attree, E. A., Barbi- eri, E., Alpini, D., Motta, A., \& Rose, F. D. (1998). Active versus passive exploration of virtual environments modulates spatial memory in MS patients: A yoked control study. Italian Journal of Neurological Sciences, 19, S424-S430.

Rizzo, A., Buck walter, J. G., Neumann, U., Kesselman, C., \& Thiebaux, M. S. (1998). Basic issues in the application of virtual reality for the assessment and rehabilitation of cognitive impairments and functional disabilities. CyberPsychology \& Behavior, 1, 59-78.

Rose, F. D., Atrree, E. A., \& Johnson, D. A. (1996). Virtual reality: An assistive technology in neurological rehabilitation. Current Opinion in Neurology, 9, 461-467.

Ruddle, R. A., Payne, S. J., \& Jones, D. M. (1997). Navigating buildings in "desk-top" virtual environments: Experimental investigations using extended navigational experience. Journal of Experimental Psychology: Applied, 3, 143-159.

Sandstrom, N. J., Kaufman, J., \& Huettel, S. A. (1998). Males and females use different distal cues in a virtual environment navigation task. Cognitive Brain Research, 6, 351-360.

Skelton, R. W., Bukach, C., Laurance, H. E., Thomas, K. G. F., \& JACOBS, W. J. (2000). Humans with traumatic brain injuries show place-learning deficits in computer-generated virtual space. Journal of Clinical \& Experimental Neuropsychology, 22, 157-175.

Sutherland, R. J., \& LingGard, R. C. (1982). Being there: A novel demonstration of latent spatial learning in the rat. Behavioral \& Neural Biology, 36, 103-107.

Suzuki, S., Augerinos, G., \& Black, A. H. (1980). Stimulus control of spatial behavior in the eight-arm maze in rats. Learning \& Motivation, 11, 1-18.

Thomas, K. G. F., Laurance, H. E., Luczak, S. E., \& Jacobs, W. J. (1999). Age-related changes in a human cognitive mapping system: Data from a computer-generated environment. CyberPsychology \& Behavior, 2, 545-566.

Tlauka, M., \& Wilson, P. N. (1996). Orientation-free representations from navigation through a computer-simulated environment. Environment \& Behavior, 28, 647-664.

Tolman, E. C. (1938). The determiners of behavior at a choice point. Psychological Review, 45, 1-41.

Tolman, E. C. (1948). Cognitive maps in rats and men. Psychological Review, 55, 189-208.

WILSON, P. (1997). Use of virtual reality computing in spatial learning research. In N. Foreman \& N. Gillett (Eds.), Handbook of spatial research paradigms and methodologies: Vol. I. Spatial cognition in the child and adult (pp. 181-206). Hove, U.K.: Psychology Press.

Wilson, P., Foreman, N., \& Tlauka, M. (1997). Transfer of spatial information from a virtual to a real environment. Human Factors, 39, 526-531.

Zentall, T. R., Sutton, J. E., \& Sherburne, L. M. (1996). True imitative learning in pigeons. Psychological Science, 7, 343-346.

\section{NOTES}

1. A virtual environment, "the representation of a computer model or database which can be interactively experienced and manipulated by the virtual environment participant(s)" (Furness \& Barfield, 1995, p. 4), is typically described as either "immersive" or "nonimmersive." In an immersive VE, the sensory aspects of the computer-generated environment are delivered to the user via specialized hardware, such as headmounted displays, data gloves, and body suits. In a nonimmersive VE, such as the one described in the present paper, the sensory aspects of the environment are delivered to the user via personal computer hardware. The participant typically controls movement within the computergenerated environment by means of a joystick, and specialized software records data about those movements (for more detailed discussions of virtual reality technology, its terminology, and applications, see Aukstakalnis \& Blatner, 1992; Barfield \& Furness, 1995; Pimentel \& Teixiera, 1995; and Rizzo et al., 1998).

2. Skelton et al. (2000) have demonstrated that the C-G Arena has good external validity.

3. To download the C-G Arena software package and to view a realtime video and figures illustrating the computer-generated space, please visit http://w3.arizona.edu/ arg/data.html. Please note that the C-G 
Arena software can be run only on Pentium 90 with MMX equivalent (or better) machines. Complete specifications of hardware and software required to run the C-G Arena are provided at the above-listed website.

4. The C-G Arena room, target, and motion variables outlined in Table 1 and the C-G Arena trial parameters outlined in Tables 4, 7, and 9 can be easily manipulated through a user interface (the Experiment Editor program that comes as part of the C-G Arena software package). In other words, specifying, for example, the dimensions of C-G Arena rooms, the size, location, and condition of the target (visible, invisible, or absent), and the number of trials does not require any knowledge of $\mathrm{C}++$, the language in which the source code of the $\mathrm{C}-\mathrm{G}$ Arena software was written, or of any other programming language. 5. The Experiment Editor user interface can also be used to change the appearance of C-G Arena rooms. For example, one can change the textures of the walls, floor, and ceiling, and, with access to graphic design or image editing software, one can mount almost any landmark, picture, or scene on the walls. To download several different examples of C-G experimental rooms, please visit http://w3.arizona.edu/ arg/ data.html.

6. The first data file is created in a format that allows it to be easily imported into standard spreadsheet and data analysis software programs. The second data file can be accessed using the Experiment Viewer pro- gram that comes as part of the C-G Arena software package and easily exports in a format compatible with standard graphic design and image editing software.

7. For instance, the failure to find group differences on the relocation trial may be attributed to the fact that very few exposures to this relatively simple virtual environment may be enough to form (at least) a coarsely grained cognitive map. (Given such a scenario, the remaining acquisition trials would simply be a matter of refining the grain of that map; see Laurance et al., 2001.) Furthermore, the pattern of data obtained in this experiment is not entirely outside the range of what has been found in animal studies of the latent learning effect; Kimble (1961), in a review of that literature, states that "the latent learning effect is frequently weak and transitory ... [and] in many experiments, it failed to appear at all" (p. 229; see also Dabrowska, 1963a, 1963b, and Muenzinger \& Conrad, 1953).

8. The slice was chosen because it provides the optimal view of the activation. Some voxels of the cluster are not shown in Figure 2 because they were either in front of or behind the slice presented in the figure.

(Manuscript received January 31, 2000; revision accepted for publication August 25, 2000.) 